\title{
Relações de "poder" e legendagem: revisitando o conceito de "poder" como substantivo autoritário para verbo de ação no processo tradutório
}

\section{Power relations and subtitling: from the concept of power as an authoritarian noun to an action verb in the translation process}

\author{
FERNANDA SILVEIRA BOITO* \\ LILIAM CRISTINA MARINS*
}

Resumo: As discussões desenvolvidas a partir do texto traduzido demonstram ser especialmente férteis na empreitada cujo foco está na problematização da linguagem, na diferença, bem como nas discussões acerca das relações de poder e resistência (RAJAGOPALAN 2007; CORACINI 2010). Nosso objetivo é, assim, discutir as relações de poder e resistência da/pela/na tradução para legendas. Para tanto, recorre-se a um recorte das legendas do documentário Lixo Extraordinário (2009), de Vik Muniz, a fim de sinalizar como a presença do outro se materializa nas escolhas tradutórias e transforma-se em um ato de revelação de alteridades. Olhar para a tradução pelas lentes da diferença pode possibilitar uma revisitação do substantivo "poder", enquanto representativo de uma autoridade absoluta de um centro sobre

\footnotetext{
"Professora Assistente do Bacharelado em Tradução da Universidade Estadual de Maringá (UEM). E-mail: fer_boito@hotmail.com

"Professora Adjunta do Bacharelado em Tradução da Universidade Estadual de Maringá (UEM). E-mail: liliamchris@hotmail.com
} 
uma periferia, para o verbo "poder", que representa capacidade e a oportunidade de realizar algo.

Palavras-chave: Tradução; “Poder”; Resistência; Legenda.

Abstract: Discussions conducted on the basis of translated texts reveal particularly fruitful when problematizing language and difference, as well as discussing power relations and resistance (RAJAGOPALAN, 2007; CORACINI, 2010). Thus, our aim is to discuss power relations and resistance of/through/in subtitle translation. To this end, we call upon a subtitle cutout taken from the documentary Waste Land (translated into Brazilian Portuguese as Lixo Extraordinário) (2009), produced by Vik Muniz, so as to analyze how the presence of the other is materialized in the translator's choices and, thus, becomes an act of revelation of otherness. Looking at translation through the lens of difference allows us to revisit the noun "power", as representation of absolute authority of a given center over periphery, to the verb that represents ability and opportunity to have things done.

Keywords: Translation; "Power”; Resistance; Subtitle.

\section{Linguagem e tradução: arena plural de crítica e agência política}

Vivemos em um mundo marcado pela diferença e pela desigualdade onde pessoas e pensamentos são excluídos, têm suas vozes silenciadas, são constantemente rejeitados e desacreditados por uma ordem dominante regularizada por relações de poder (CORACINI 2010). Essas vozes que, segundo a autora, são (des)ordenadas, (in)fames e silenciadas em um determinado momento sócio-histórico, ao mesmo tempo, buscam formas de resistir ao poder e à ordem sufocante "que constrói identidades, nelas fixa estereótipos, discriminações, produzindo subjetividades que não encontram lugar nas sociedades hegemônicas de discurso" (CORACINI 2010: 107).

Este nos parece ser o caso dos sujeitos catadores de lixo - ou material reciclável como eles preferem dizer - que, por trabalharem entre/no lixo e fazerem deste seu material de sustento, seu meio de vida, são marginalizados 
pela sociedade dominante e estigmatizados por ela, permanecendo ignorados, sem fama e rotulados por estereótipos vitimizadores ou opressores. No entanto, esses sujeitos encontram também maneiras de resistir e de fazer ressoar sua voz, assim como os sujeitos em situação de reclusão investigados por Coracini (2010):

Como são cada vez menos vistos, como alguns os querem ainda mais apagados, riscados, escamoteados dessa sociedade, eles são chamados de excluídos. Mas, ao contrário, eles estão lá, apertados, encarcerados, incluídos até a medula! (FORRESTER apud CORACINI 2010: 124).

Também nos parece ser esse o caso da tradução para legendas, modalidade tradutória que é alvo frequente de críticas por parte dos espectadores e, não raro, considerada pelo senso comum, e até mesmo por estudiosos da tradução, enquanto obra "menor", principalmente quando comparada à tradução de textos em suporte impresso. Entretanto, essa modalidade de tradução, de modo semelhante ao sujeito catador, também resiste.

Nessa medida, o presente artigo tem por objetivo discutir as relações de poder e resistência da/pela/na tradução para legendas. Para tanto, trazemos um recorte do documentário Lixo Extraordinário (2009) ${ }^{1}$ para exemplificar como a presença do outro materializa-se como um ato de revelação da alteridade das línguas, culturas e discursos e, a partir disso, discutir a respeito das relações de poder e resistência. Consideramos fundamental destacar ainda que a presente discussão envolvendo os estudos da tradução, os sujeitos catadores de lixo, bem como relações de poder e resistência, se faz importante na medida em que somos cada vez mais convocados a refletir sobre a língua enquanto prática social central na constituição dos modos como nos constituímos e construímos sentido no mundo.

Sendo assim, a linguagem não só atravessa e constitui subjetividades, mas intervém na realidade social na qual ela se situa (RAJAGOPALAN 2007).

\footnotetext{
${ }^{1}$ A obra audiovisual em questão foi produzida a partir de uma parceria entre produtoras brasileiras e inglesas e acompanhou o trabalho do artista plástico Vik Muniz desenvolvido com catadores de lixo no aterro sanitário Jardim Gramacho na cidade do Rio de Janeiro.
} 
Abordar a língua(gem) sob esse viés abre espaço para o pensamento crítico e pensar na linguagem criticamente significa partir do princípio de que ela é sempre "atravessada pelas conotações político-ideológicas" (RAJAGOPALAN 2007: 19). Dessa forma, somos capazes de realizar, através de discussões linguísticas, um trabalho político que considera questões sobre poder e desigualdade e que fomenta debates importantes a respeito de cidadania, representação, exclusão e inclusão social, chamado a atenção para aquilo que, por muito tempo, permaneceu encoberto e calado.

Pennycook (1998) também argumenta em defesa de um olhar mais crítico e sensível para a linguagem, que precisa se voltar para as preocupações sociais, culturais e políticas. Trata-se de engajarmo-nos em um movimento que busque não somente compreender as iniquidades que caracterizam o mundo em que vivemos, mas que também procure criticá-lo e, assim, transformá-lo. Nesse sentido, ao falarmos de crítica, não nos referimos a um criticismo negativo cujo objetivo é meramente apontar falhas ou posicionar-se contra, mas de crítica enquanto possibilitadora e causadora de crises, desestabilização e ruptura que permitem uma abertura e uma consequente emancipação do pensamento e das práticas sociais.

Ou seja, ao direcionarmos um olhar crítico à nossa volta, principalmente à linguagem e, no caso do presente texto, à tradução, somos capazes de investigar e entender as circunstâncias específicas geradoras de sentidos e, consequentemente, de iniquidades opressoras, e, assim, provocar mudanças:

Se estamos preocupados com as óbvias e múltiplas iniquidades da sociedade e com o mundo em que vivemos, então creio que é hora de começarmos a assumir projetos políticos e morais para mudar estas circunstâncias. Isso requer que rompamos com os modos de investigação que sejam associais, apolíticos e a-históricos (PENNYCOOK, 1998: 46).

Para Rajagopalan (2007: 16), a necessidade de refletirmos teoricamente sobre a linguagem pelas lentes da crítica é algo recente, em torno de três décadas, e está se fundamentando a partir de uma noção de linguagem como algo que vai além de um simples espelho de como é a mente 
humana. Não se trata de uma parede que separa a mente e o mundo, mas de um lócus de intervenção, já que revela as injustiças sociais pelas quais diferentes grupos passam e representa também as lutas que são travadas constantemente. Quando nos damos conta de que é possível reagir e resistir pela linguagem, e por que não afirmar por meio da tradução, é que a percepção crítica se revela, pois "trabalhar com a linguagem é necessariamente agir politicamente, com toda a responsabilidade ética que isso acarreta".

Partindo dessa visão crítica, somos levados a reavaliar algumas crenças ancoradas em um modo positivista de pensamento e conhecimento. Essa reavaliação inclui repensar a fé em um sujeito indivisível, consciente, dono e conhecedor de si; noções de objetividade, verdade e universalidade do sujeito e dos significados construídos por ele; a concepção de que o pensamento é anterior à linguagem e, portanto, passível de ser transmitido com neutralidade; a ideia de que existe uma essência e uma realidade preexistentes; e a visão de língua(gem) enquanto sistema e estrutura, um instrumento apolítico, a-histórico e acultural cujo papel se afasta do modo como concebemos o mundo e a nós mesmos.

Por esse viés, somos conduzidos também por um caminho de problematização, prática que caracteriza os estudos pós-modernos sobre tradução, de alguns conceitos, noções e crenças fortemente vinculadas aos dizeres mais tradicionais e prescritivos sobre tradução, a citar: a figura de um tradutor consciente e neutro, que opera simplesmente como mediador do transporte de uma mensagem; do texto "original" enquanto receptáculo de uma verdade, um sentido e uma essência intocáveis; da tradução enquanto mecanismo de transferência imparcial que opera com línguas vistas como sistemas que se correspondem.

Ao assumirmos tal postura pós-moderna, questionando um modo de pensar herdado do lluminismo, passamos a conceber a língua(gem) como "um sistema de significação primária pelo qual fazemos sentido no mundo" (PENNYCOOK 1998: 28), constituímos nossa subjetividade, enquanto sujeitos (hiper)complexos, híbridos, cindidos que somos, e que funciona para manter e 
mudar as relações de poder e as desigualdades. De modo semelhante, passamos a conceber a tradução enquanto a materialização deste conceito de língua(gem) e, assim, de uma leitura-interpretação possível, a produção de um texto outro que é heterogêneo e repleto de vozes, um processo em que o tradutor tem papel agente, que não reproduz, mas constrói e reconstrói conhecimento.

Como a noção de agência aqui adotada engloba as possibilidades do discurso, as perspectivas que defendem a existência de verdades absolutas, como a de leituras que sustentam um único significado, são evitadas. A língua(gem) é, portanto, um lugar importante de luta política (PENNYCOOK 1998) e a tradução uma arena complexa onde diferentes modos de significação do mundo, diferentes vozes e práticas distintas entram em conflito.

\section{Tradução e outras vozes: do "poder" às possibilidades}

Os estudos da tradução e as discussões desenvolvidas a partir do texto traduzido demonstram ser especialmente férteis na empreitada cujo foco está na problematização da linguagem, na diferença, bem como nas discussões acerca das relações de poder e resistência. Isso, pois, por estar inserida na tensão entre culturas e discursos e ao trabalhar nas redes de diferenças entre língua de partida e língua de chegada, a tradução desestabiliza a noção de verdades absolutas, prontas, acabadas e superiores, abalando as posições (ditas fixas) do que permanece no centro e do que é periférico, e sinaliza para a pluralidade não só de vozes, mas também de sentidos que sempre podem ser outros.

Com base nas discussões propostas por Arrojo (2013), que parte de um conceito nietzschiano, falar sobre a desestabilização da noção de verdade, neste contexto, sinaliza a importância de questionarmos a vontade de 
verdade que sentimos, ou seja, enquanto sujeitos socio-histórico-sociais, há em nós o desejo de pregar para o outro a necessidade de "conversão" à verdade que "pregamos", o que supriria, assim, nosso desejo de poder. Ao pregarmos nossa verdade, tolhemos, consequentemente, a capacidade de (re)construir do outro e negamos a ele a possibilidade de fazer diferente, por isso, segunda a autora, é preciso problematizar a vontade de verdade.

Nesse sentido, a tradução, ao fazer saltar aos olhos aquilo que é diferente, incomoda e perturba a ordem dominante, desestabilizando a verdade que, em algum momento, foi apresentada como hegemônica e superior, revelando outros lados, outras vozes, outras verdades, sentidos e sujeitos. Por meio da tradução e das diferenças trazidas à tona a partir dela, somos levados a questionar a vontade de exercer o poder no outro em várias instâncias: na relação entre línguas, em que uma seria hierarquicamente superior à outra; na oposição entre "original" e tradução, em que, muitas vezes, o texto "original" é alocado em posição de maior importância; na relação entre autor e tradutor, na qual o primeiro é frequentemente (mesmo que utopicamente) considerado autoridade sobre aquele que traduz; no que diz respeito ao sentido, questionando a supremacia de um sobre o outro; ou ainda nas modalidades tradutórias, como nos casos em que um determinado gênero textual é mais sacralizado que outro.

Isso significa que olhar para a tradução pelas lentes da diferença e, consequentemente, da pluralidade e não da igualdade, pode possibilitar, em um mundo multi-(facetado, cultural, lingual, letrado etc.), uma revisitação do substantivo "poder", enquanto representativo de uma autoridade absoluta de um centro sobre uma periferia, para o verbo "poder", que representa capacidade e a oportunidade de realizar algo. Reconhecer esta capacidade torna possível, assim, legitimar a minha voz e também as vozes dos outros.

\subsection{A resistência da tradução para legendas}


A fim de ilustrar como outras vozes podem se marcar na/pela tradução através da diferença, permitindo, assim, que a pluralidade, as possibilidades e, consequentemente, a resistência venham à tona, trazemos o recorte discursivo a seguir. Neste recorte, observamos que a manutenção do termo em língua portuguesa na legenda escrita em língua inglesa dá lugar de destaque à diferença:

\begin{tabular}{|l|l|}
\hline \multicolumn{1}{|c|}{ ÁUDIO (Português) } & \multicolumn{1}{|c|}{ LEGENDA (Inglês) } \\
\hline & 432 \\
& $00: 34: 42,056$--> 00:34:45,359 \\
& It's quiet now because there are no \\
Agora que tá, tá mais calmo porque & wars between the favelas. \\
não tá tendo guerra nas favela. & 433 \\
Mas se tivé guerra em favela... & $00: 34: 45,359$--> 00:34:47,554 \\
& But when there are wars between \\
& the \\
& favelas... \\
\hline
\end{tabular}

A presença do outro, marcada pela manutenção do termo "favela" em língua portuguesa, materializa-se enquanto um ato de revelação da alteridade: da diferença entre as línguas, das culturas, dos discursos e dos leitores; do tradutor e do processo tradutório. Essa presença causa certo estranhamento, um desconforto, pois traz à tona a heterogeneidade $\mathrm{e}$ pluralidade de sentidos e vozes que falam no texto traduzido e, assim, torna o processo tradutório visível, notável. Isso leva à desestabilização não só dos sentidos, mas do texto traduzido que deixa de se revelar enquanto (ilusoriamente) neutro, imparcial e transparente, além de sinalizar para a ideia de que as fronteiras entre o texto original e a tradução são fluidas, nãoestanques, mas se entrecruzam a todo o tempo, marcando a presença de um no outro.

A presença desse outro na legenda abala a noção de que o sentido do termo "favela" é único, estanque e, portanto, deveria ser traduzido diretamente para a língua inglesa somente de acordo com as opções dicionarizadas (como seria o caso de "slum" ou "shantytown"), como se fosse 
possível a simples transferência da "essência" da língua portuguesa para a língua inglesa.

Falar da favela do Rio de Janeiro é falar não somente de um lugar com condições organizacionais específicas e habitado por indivíduos marginalizados socialmente, mas é falar de sua história - intimamente ligada à teia dos dizeres e dos acontecimentos a respeito da escravidão (VALADARES 2000) - e de seu "status" atual também enquanto lugar de turismo, consumível e explorável comercialmente.

Essa leitura que fazemos a partir do termo "favela" nos leva a observar que a opção pelo termo em língua portuguesa sinaliza para as marcas culturais do texto de partida, das ressonâncias discursivas da cultura da favela no Rio de Janeiro, de vozes e discursos que falam da e na favela. Sendo assim, é possível pensar que os termos dicionarizados não estariam na mesma teia de discursos e dizeres e, possivelmente, criariam efeitos de sentidos diferentes.

Isso significa que a manutenção do termo em língua portuguesa materializa a tensão que ocorre na construção dos sentidos pelo tradutor no processo de leitura-tradução. Nesse processo de construção, os sentidos são sempre instáveis e adiados, como diria Derrida (2001), e não coincidem de uma língua para outra, negando a possibilidade de transferência e recuperação, e trazendo à superfície a indecidibilidade e a pluralidade.

o recorte discursivo supracitado nos leva ainda a afirmar que a diferença marcada, ao trazer à tona o híbrido e o heterogêneo, dá destaque à tradução. Há um estranhamento que sinaliza para as possibilidades, o que, por sua vez, chama a atenção para a noção de que a produção de efeitos de fluência, transparência e homogeneidade por parte do texto traduzido e do tradutor é ilusória. Sendo assim, a presença gritante do outro faz com que os sentidos deixem de ser vistos enquanto verdades absolutas, mas enquanto possibilidades. Como desdobramento, a neutralidade e a imparcialidade do tradutor também são desconstruídas e a legenda passa, assim, a ser visível e protagonista, o que materializa sua resistência.

A tradução (em todas as suas formas) ocupou, por muito tempo, uma posição periférica em um espaço cultural que (ainda) valoriza o "original" 
como "sagrado". No entanto, se hoje temos um campo do saber que contempla os estudos da tradução, isso se deve muito a sua luta por existir e conseguir, assim, resistir.

As relações de poder são, para Santos (2002), sempre pautadas em polarizações e dualismos tanto inibidores quanto permissivos (por exemplo, incluído versus excluído), o que permite traçarmos um paralelo com o conceito de tradução nas vertentes mais tradicionais. Nessas vertentes, buscava-se destacar a hierarquia institucionalizada entre texto "original" e texto traduzido com o objetivo de mostrar que há uma relação de poder na relação entre texto de partida e de chegada.

Devido a essas relações de poder, com base nos pressupostos de Foucault (2000), Olher (2010) atesta que, conforme o poder se estabelece, surgem, concomitantemente a esse processo, os discursos legitimados, como o de que o texto de partida tem mais valor que sua tradução.

A dominação que o original exerce sobre a tradução coíbe 0 estabelecimento de novos papeis devido a esse controle e reforça ideias culturalmente determinadas, as quais apontam para uma verticalização do poder, em que o original está sempre em uma posição superior. É nesse sentido que as teorias pós-modernas, partindo de uma visão desconstrutivista, propuseram uma horizontalização da relação de interdependência entre original e tradução, colocando na berlinda uma perspectiva logocêntrica, na qual se recorrem às polaridades para estabelecer relações de poder.

Quando tratamos de tradução para legendas, podemos pensar em um poder ainda mais forte e escancarado exercido pelo "original", porém, ao mesmo tempo, também vislumbramos resistência. Ao ser exibida em sincronia com o áudio, ou seja, o texto sonoro de partida, a legenda é submetida à suposta supremacia daquele e o legendador é exposto aos questionamentos do público em relação a uma utópica “fidelidade linguística” não alcançada. Ou seja, a presença do áudio original pode (res)suscitar dizeres e conceitos mais tradicionais a respeito da tradução, principalmente por permitir o cotejo, isto é, a comparação direta entre "original” e tradução por parte do espectador cujas leituras sempre poderão diferir daquelas materializadas pelo tradutor. 
Nesse movimento de comparação, a "fidelidade" pode ser questionada e o trabalho do legendador torna-se alvo de críticas.

Além disso, dentro dos estudos da tradução, a legenda ainda é marginalizada tanto por estar associada à imagem, quanto por seguir regras que podem limitar as escolhas tradutórias. 0 texto legendado, submetido ao poder e abafado pela presença imponente e opressora do texto sonoro de partida, é ainda mais desacreditado por ser exibido em sincronia com a imagem que, em alguns contextos da sociedade atual que têm como referência a cultura grafocêntrica e o suporte impresso, seria "inferior" à linguagem verbal. Ademais, sua produção deve respeitar normas e padrões estabelecidos pelos clientes e produtoras audiovisuais, em um movimento em que nem tudo pode ser dito de qualquer modo, em qualquer lugar e por qualquer um.

A tentativa de controle, por exemplo, de palavras consideradas proibidas (e aqui fazemos referência a um dos dispositivos de controle do discurso desenvolvidos por Foucault, 1995), ou seja, da linguagem considerada "apropriada" pelos manuais/guias de estilo, certamente, influencia as escolhas do tradutor e cria efeitos de sentidos diferentes do que aqueles que seriam construídos se a linguagem "banida" fosse, por outro lado, considerada.

De acordo com Santos (2002), o poder é qualquer relação social que seja determinada por uma troca que não se baseia no princípio de igualdade, ou seja, tanto no aspecto material quanto não material, sendo que a segunda está atrelada a primeira. Isso significa que a desigualdade material leva, também, à desigualdade das capacidades de representação e comunicação e a desigualdade de ter oportunidades para participar de escolhas. Esta relação social, no processo de legendagem, está marcada pelo poder exercido pela produtora, que é o agente que contrata o trabalho do tradutor e fornece esses manuais e regras a serem seguidas por eles, em relação ao tradutor, que, por estar à mercê deste poder, tem sua capacidade de fazer escolhas limitadas.

Nessa perspectiva, a tomada de determinada decisão, a escolha de determinado termo em detrimento de outro, já revela uma rede de relações 
que não é imparcial e que, por sua vez, também revela as tensões que são provocadas pelo poder (ÁvILA 2013). Como traduzir é negociar sentidos em um processo de (re)escritura, há, no texto, aspectos culturais e ideológicos que são deixados como vestígios, como assinaturas do tradutor, mesmo em meio a esses cerceamentos, confirmando a impossibilidade de imparcialidade e neutralidade na tradução e reafirmando o espaço para a resistência.

Uma relação social se transforma em uma relação de poder quando os interesses de um afetam os interesses de outro, em uma direção contrária. Por isso, a partir de uma visão teórico-crítica, estabelecemos, ao invés de relação de poder, relações de emancipação, as quais possam dar suporte não para a reprodução do poder, mas de sua destruição (SANTOS 2002). E este parece ser o caso da modalidade de tradução para legendas, pois ela se faz presente, resiste ao poder do texto original e também da língua estrangeira que mais representa o poder atualmente: a língua inglesa.

\subsection{A resistência do catador de lixo na tradução para legendas}

Tratamos, até aqui, das reflexões acerca da resistência da legendagem. Nesta seção, discutiremos sobre a resistência do sujeito catador de lixo no texto traduzido, partindo do mesmo recorte discursivo destacado anteriormente.

Com o termo "favela" mantido em língua portuguesa na tradução em língua inglesa, chamamos a atenção para o destaque à diferença que permite que uma gama de vozes fale na tensão do entre-lugar das línguas-culturas: a voz do tradutor, do estrangeiro, da favela - sua história; a favela carioca ligada ao turismo enquanto atividade altamente lucrativa e disputada, vendida e consumida; enquanto marca registrada, a partir da qual muitos produtos têm sido desenvolvidos e comercializados; um conjunto de 
aglomerados pobres, de ocupação ilegal e irregular; lugar de indivíduos marginalizados, excluídos, esquecidos e silenciados; e a voz do catador.

No recorte discursivo analisado, em conversa com o artista plástico e os produtores do documentário, um dos catadores que trabalha em Jardim Gramacho e mora em uma favela descreve como está a situação naquele contexto. A favela é o lugar de moradia desse catador, onde ele e sua família vivem e com o qual esse indivíduo estabelece laços de proximidade. Acreditamos ainda poder ir além disso: é com a favela que o catador estabelece vínculos que o constituem também enquanto sujeito, uma vez que o contexto sócio-histórico-cultural da favela vai contribuir para constituir e determinar os modos de significação desse sujeito no mundo. Portanto, falar e dar destaque à favela, aqui, é também falar e dar destaque ao catador.

A opção em manter o termo "favela" em língua portuguesa no texto traduzido para a língua inglesa permite que as vozes que falam na e da favela, incluindo a voz do catador, permaneçam também no texto de chegada. Essa manutenção coloca o outro em evidência, fazendo com que os leitoresespectadores da cultura de chegada tenham contato com os modos de significação da cultura de partida, e por que não também afirmar o contato com os sujeitos dela, levando esses leitores a uma prova, uma experiência do estrangeiro (VENUTI 1995).

Por se fazer presente na tradução através do termo favela, o catador se marca, logo, tem sua voz materializada na tradução. Isso nos leva a concluir que a tradução age enquanto instrumento de fala do sujeito catador que, através do texto traduzido, surge pelas frestas e resiste a um poder opressor que silencia e marginaliza. Aqui a tradução para legendas age enquanto materialização de uma prática de resistência na qual as vozes da favela e do sujeito catador, por intermédio da voz do tradutor, encontram uma maneira de falar e, assim, resistir. 


\section{Considerações finais}

O objetivo deste artigo foi discutir as relações de poder e resistência da/pela/na tradução para legendas, partindo-se, em alguns momentos, da problematização da escolha tradutória de um recorte do documentário Lixo Extraordinário (2009), de Vik Muniz. A análise da manutenção do termo "favela" em português na legenda do documentário mostrou que o catador resiste na tradução, pois faz ressoar a voz da favela e do catador, diferentemente do que aconteceria se a opção fosse por um termo em inglês. $\mathrm{Na}$ legenda, tanto o catador quanto a tradução, ambos historicamente assujeitados aos padrões dominantes (que determinam que ser catador não é um trabalho prestigiado socialmente e que o "original" é portador dos significados verdadeiros, respectivamente), conquistam visibilidade no momento em que a diferença, força motriz dos estudos pós-modernos da tradução, se materializa na linguagem.

Olhar para a tradução pelas lentes do outro pode possibilitar, assim, uma revisitação do substantivo "poder", enquanto representativo de uma autoridade absoluta de um centro sobre uma periferia, para o verbo "poder", que representa a capacidade e a oportunidade de realizar algo. Reconhecer esta capacidade torna possível, assim, legitimar a minha voz e também as vozes dos outros.

Quando nos damos conta de que é possível reagir e resistir pela linguagem, e por que não dizer pela tradução, as relações de poder, que são inerentes à sociedade e à linguagem, são deslocadas. Esse deslocamento somente se torna possível quando passamos a olhar para a língua criticamente, ou seja, como uma prática social.

\section{Referências bibliográficas:}

ARRoJo, R. Escrita, interpretação e a luta pelo poder no controle do significado: cenas de Kafka, Borges e Kosztolányi. In: Blume, R. F.; Peterle, P. (Orgs) Tradução e relaçães de poder. Tubarão: Ed. Copiart, Florianópolis: PGET/UFSC, 2013: 69-94. 
ÁVILA, E. S. Pode o tradutor ouvir? In: Blume, R. F.; Peterle, P. (Orgs) Tradução e relações de poder. Tubarão: Ed. Copiart, Florianópolis: PGET/UFSC, 2013: 21-68.

CoRACINI, M. J. Vozes (des)ordenadas e (in)fames. In: A (des)ordem do discurso. Org.: Mianez, N; Gaspar, N. R. São Paulo: Contexto, 2010, pp. 105-126.

DerRIDA, J. Posições: Jacques Derrida. Tradução de Tomaz Tadeu da Silva. Belo Horizonte: Autêntica, 2001 [1972].

Foucault, M. A ordem do discurso. In: Souza, A. 0. Apontamentos. Maringá: EDUEM, 1995, pp. 6-30.

LIXO EXTRAORDINÁRIO (filme). Direção Lucy Walker. Edição Pedro Kos. Produção Angus Aynsley e Hank Levine. Coprodução Peter Martin. Rio de Janeiro: 02 Filmes, 2009. 99 min.

OLHER, R. M. Heterogeneidade nas representações de tradução em contexto de ensino superior de literaturas estrangeiras: um lugar "entre-línguas". Tradução \& Comunicação: Revista Brasileira de Tradutores, São Paulo, v. 20, 2010, pp. 113-126.

Pennycook, A. A Linguística Aplicada nos anos 90: em defesa de uma abordagem crítica. In: Signorini, I.; Cavalcanti, M. C. Linguística Aplicada e transdisciplinaridade. Campinas: Mercado das Letras, 1998: 23-49.

Rajagopalan, K. Por uma lingüística crítica: linguagem, identidade e questão ética. São Paulo: Parábola Editorial, 2003.

SANTOS, B. S. Crítica à razão indolente: contra o desperdício da experiência. São Paulo: Cortez, 2002.

VAlLADARES, L. A gênese da favela carioca: a produção anterior às ciências sociais. Revista Brasileira de Ciências Sociais, São Paulo, v. 15, n. 44, out. 2000: 5-34.

VENUTI, L. The Translator's Invisibility: a history of translation. London; New York: Routledge, 1995. 